\title{
INITIAL SURVEY ON INTERACTION OF ELDERLY PEOPLE WITH SMARTPHONES
}

\author{
Adrian KAPCZYŃSKI ${ }^{1 *}$, Marcin LAWNIK ${ }^{2}$ \\ ${ }^{1}$ Silesian University of Technology, Gliwice; adrian.kapczynski@polsl.pl, ORCID: 0000-0002-9299-1467 \\ ${ }^{2}$ Silesian University of Technology, Gliwice; marcin.lawnikpolsl.pl, ORCID: 0000-0002-0235-0878 \\ * Correspondence author
}

Purpose: This paper is devoted to elderly people and their interaction with smartphones. The analysis of the state of the art inspired the formulation of research questions related to interaction of elderly people with smartphones, e.g. how do they input data or how do they start the SOS signal.

Design/methodology/approach: In order to answer the research questions, an electronic questionnaire was prepared and executed. The survey consisted of 11 questions and was completed by 40 people.

Findings: The conducted research has shown that seniors are increasingly using smartphones for a variety of tasks, including (among others) text messaging and multimedia.

Originality/value: The presented research is the most current research on the behaviour of seniors using smartphones on the Polish market. The obtained results can be used, among others, when designing applications and devices for seniors.

Keywords: elderly people, smart society, mobile devices.

Category of the paper: Research paper.

\section{Introduction}

We live in times of constantly developing technical solutions and we are the witnesses of significant demographic changes (Cearley, and Burke, 2019; UN DESA, 2018). There are more and more sophisticated technical achievements, while the distribution of a world's population has shifted towards older ages.

The idea of conducting the research in the area of interaction of older people with intelligent devices arose from three prerequisites: (1) the observation made at Silesian University of Technology during classes at University of the Third Age initiative, (2) research projects carried out in the area of mobile interfaces and (3) student technical projects realized under the laboratory classes "Multimedia mobile interfaces". 
Elderly people who participated in practical classes at University of the Third Age have identified the need for efficient use of smartphones as being particularly important. The research projects carried out were focused on the technical aspects of human-machine interaction, in which only issues related to the availability of digital content were considered, without taking into account the specificity of older people as smartphone users. And finally, student projects concerned the design of interfaces, within which special attention was paid to the technical possibilities of implementing the usability of mobile applications, leaving open questions about interface design in terms of the needs of older people.

The aim of this article is to conduct preliminary research in the field of interaction of elderly people with mobile devices.

The layout of the content of this article includes: introduction, current state of the art, research results and conclusions. In the introduction, the motivation, goal of the study and layout of the content were presented. The current state of the art includes the results of a literature review regarding the interaction of older people with mobile devices. The most important is the part devoted to the conducted research. The entire article closes with the conclusions, which indicates directions for further research.

\section{State of the art}

The literature on the subject concerning the use of mobile devices by the elderly people is very rich. In the beginning it is worth noting that the current results of the conducted research indicate a wide spectrum of analysed issues, as well as show rich possibilities of conducting deepening research projects.

One of the basic trends in literature on topics related to the use of mobile devices by elderly people is to define design patterns for application interfaces. Therefore in the following reference (Al-Razgan, et al., 2012), among others, one can find guidelines about the design of interfaces for elderly people, in the areas of: Look and Feel, Interaction and Functionality. The results of similar studies have been documented in (Wong, et al., 2010) and (GarcíaPeñalvo, et al., 2014), where recommendations for interfaces of mobile solutions that are friendly to the elderly were presented. It was emphasized how important the usability of a mobile device is and what role the multimodal interaction techniques are playing (sound, image, touch).

In turn, in (Arab et al., 2013), an example of such an interface - PhonAge, which was assessed by a group of 20 older people, was discussed. As part of the research, the daily use of mobile phone was presented, as well as the results of the test of icon meaning understanding (icon understandability test). 
In the work by (Li, and Luximon, 2018) a thorough research was conducted regarding interaction between elderly people and the smartphone. The research was focused on technology features (e.g. use of graphics, use of menus, navigation), usage behaviour (e.g. duration of use, intensity of use) and user perceptions (perceived usefulness, perceived usability, self-efficacy). They include, inter alia, opinions on the device and system interface as well as the way in which elderly people use smartphones and mobile applications. Similar research has been carried out in (Gordon, and Bigham, 2019) in the field of qualitative analysis of applications used, defined by the authors as "app usage dynamics", as well as in (Slavíček, 2014), where five different participants were interviewed about phone usage.

Some of the research focuses on users from a certain cultural circle or country. Such research can be found in (Zainal et al., 2013), where special attention was paid to recommendations for conducting an interview with an elderly person as well as in (Nasir, and Jomhari, 2008), where research project was carried out among users coming from Malaysia. Similar research was carried out in (Bhutta et al., 2018) on users from Pakistan, with particular emphasis on preferred functionalities on a smartphone and in (Leme et al., 2014) on users from Brazil, in which three profiles of users of mobile device were distinguished.

Research on elderly people also concerns the analysis of publications and thus the popularity of this subject. An example of such a work is (de Oliveira et al., 2018), where the extent to which seniors are disseminated among scientists (including publications in such databases as Scopus) was analysed. A similar analysis was carried out in (Nurgalieva et al., 2019).

In (Iqbal et al., 2017) an analysis of the usability of adaptive functions in smartphones such as screen rotation or voice commands was carried out. In turn, in (García-Peñalvo et al., 2014), the topic of smartphone utility for seniors was discussed, and the need to introduce elderlyspecific application stores was indicated. The challenge of elderly people interaction also applies to applications with a specific purpose. An example of such an application, entitled "Crossword learning" has been discussed in (de Oliveira et al., 2018).

Similar studies were also conducted in Poland (Umańska, 2016, Niemczyk, 2016, Badowska, 2016, CBOS, 2017). In (Umańska, 2016) the subject of smartphone education for elderly people was explored. It discussed the use of smartphones by elderly people at the university of the third age or an overview of smartphone-related guides for that group of people.

In turn, in (Niemczyk, 2016), the approach of elderly people towards new technologies (with particular emphasis on web technologies) was discussed. Similar studies but on a larger scale were carried out in (Badowska, 2016), where mobile technologies were also included.

In (CBOS, 2017), the Polish users of smartphones were tested on the request of CBOS in 2017. Among the group of interviewees were also seniors and the range of questions asked included how to use the phone (phone calls, SMS, etc.) or use basic applications for taking photos or browsing websites. 
The conducted literature analysis indicates a research gap regarding the current (valid for 2019) characteristics of elderly people interaction with smartphones, with particular reference to elderly people from Poland. Studies carried out in the literature are either outdated, e.g. (CBOS, 2017) or refer to other cultural circles, e.g. (Bhutta et al., 2018, Leme et al., 2014, Nasir, and Jomhari, 2008).

\section{Research results}

Authors have prepared and executed an electronic survey. The first part of the survey was prepared in order to learn about the characteristics of the person completing the survey. It consisted of questions related to gender, age, experience with smartphones and the ability to address challenges related to smartphones.

The second part of the survey was prepared to examine the interaction of the user with the smartphone and consisted of five questions:

- How do you unlock your smartphone?

- How do you interact with your smartphone?

- How do you generate an emergency signal?

- What smartphone special features do you use (e.g. larger font)?

- What improvements regarding the interaction do you expect from your smartphone?

40 people took part in the survey.

The division by age and gender is shown in Fig. 1 .
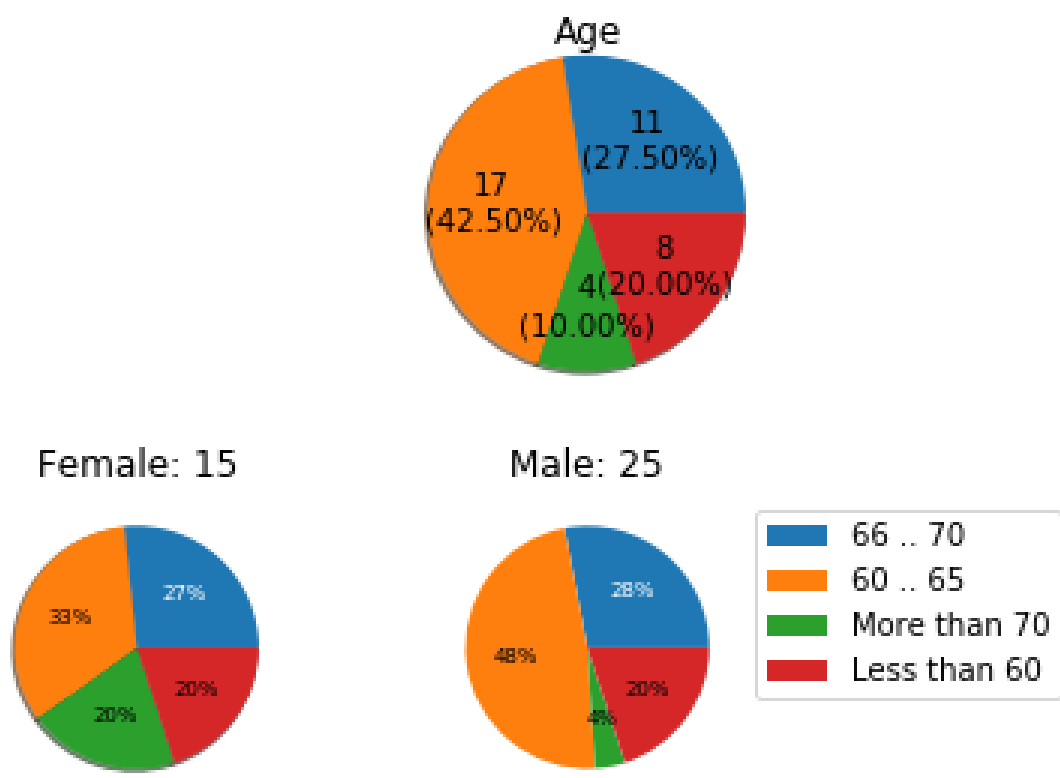

Figure 1. Distribution of people by age and gender. 
Fig. 2 contains a summary of the answers to the question "how long have you been using a smartphone?". The vast majority of respondents declared that it was 3 or more years and only 8 people indicated that it is less than a year. This means that the studied group has a lot of experience in using mobile devices.

Fig. 3 shows responses regarding making voice calls by elderly people. The vast majority declared that they do it often and only one person rarely uses this basic functionality of the smartphone.

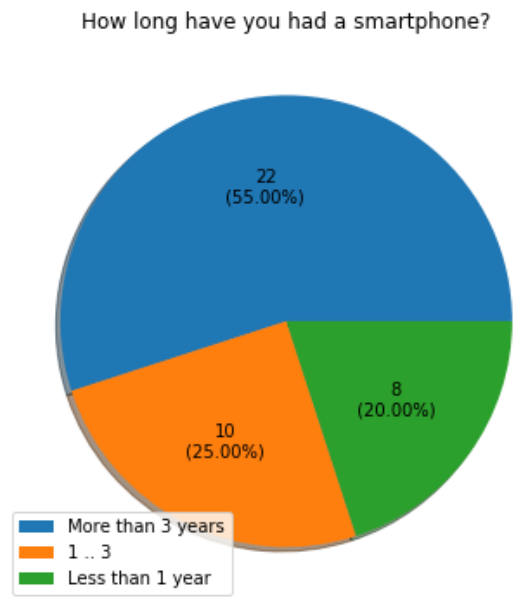

Figure 2. A summary regarding the experience in using smartphones.

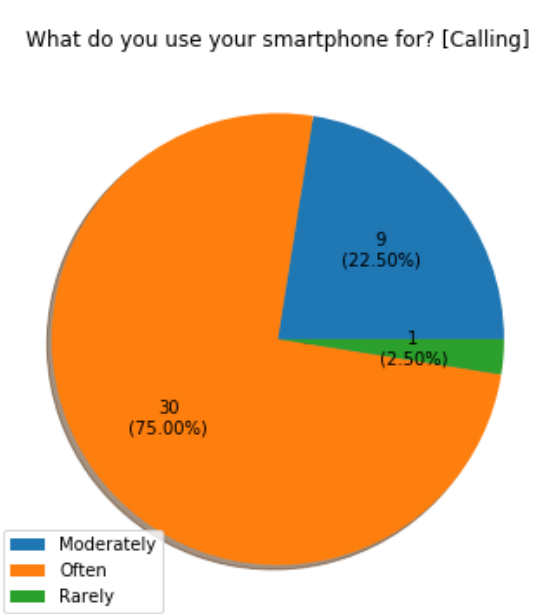

Figure 3. A summary regarding making phone calls.

In Fig. 4, the responses regarding sending or receiving text messages are presented. The vast majority of respondents declared that they do it often, but the group of people who use this functionality rarely compared to making telephone calls has grown.

Fig. 5 shows a summary of the answers to a question regarding the use of a smartphone for taking pictures and recording movies. The distribution of answers suggests that seniors often use this functionality. 
What do you use your smartphone for? [SMS]

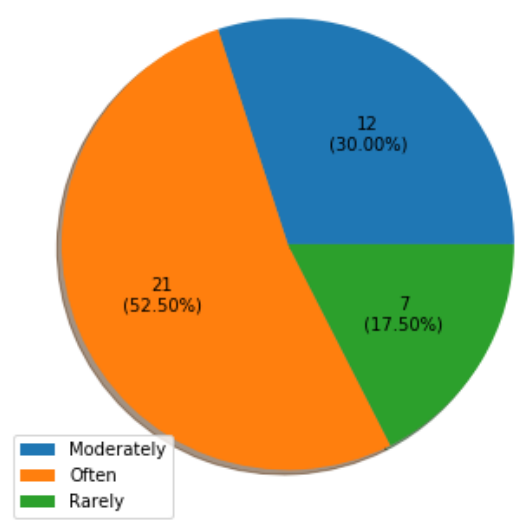

What do you use your smartphone for? [Photo]

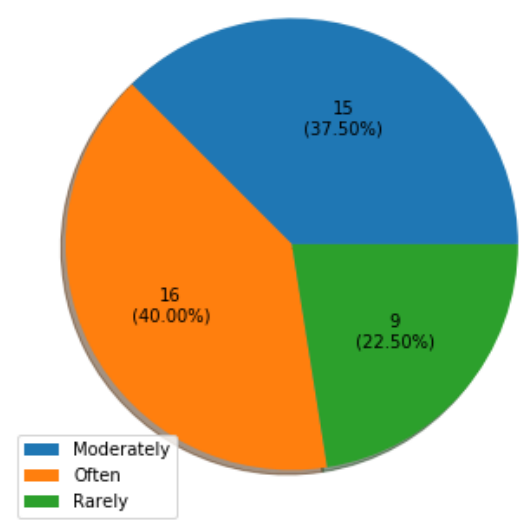

Figure 4. A summary regarding the use of SMS. Figure 5. A summary regarding taking pictures and recording movies.

Fig. 6 shows the answers to a question regarding the use of a web browser. The distribution of responses is practically uniform here. It also means that the size of the group that does not use this service has significantly increased.

Fig. 7 shows a summary of responses given about the use of a smartphone to compose or receive e-mails. In the case of this question, the vast majority responded that they rarely use this feature. This may be, for example, due to the fact that elderly people prefer either personal contact or contact by phone and rarely maintain internet contacts.

What do you use your smartphone for? [Internet browsing]

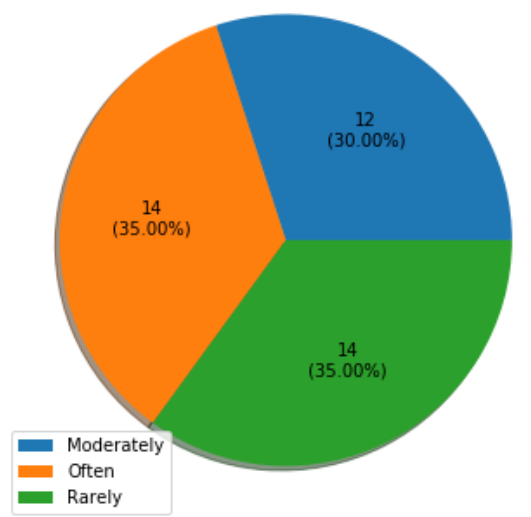

What do you use your smartphone for? [E-mail]

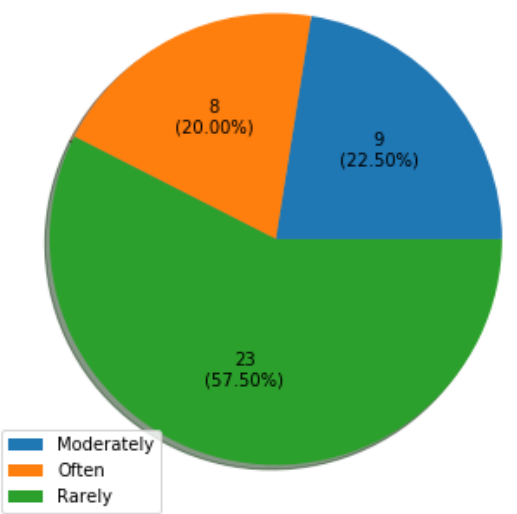

Figure 6. A summary regarding the use of a web browser.
Figure 7. A summary regarding the use of an electronic mail. 
Fig. 8 shows the use of a smartphone in an emergency situation. Only one person replied that in such a situation they would use a special SOS button. This is quite surprising, especially since most smartphones have such a built-in functionality. From the obtained results it can be concluded that the elderly people in emergency situations most frequently call the 112 emergency number. Also, the high score for the "Prefer not to reveal" answer may suggest that some respondents did not want to answer this question due to the lack of knowledge of how to make such a signal.

Fig. 9 shows a summary of responses regarding the use of help in personalizing a smartphone or to cope with new challenges. The distribution of answers is fairly uniform. What may seem surprising is the result for a group that can cope without help. This can be explained by the considerable experience of the users surveyed (see Fig. 2).

How do you generate an emergency signal?

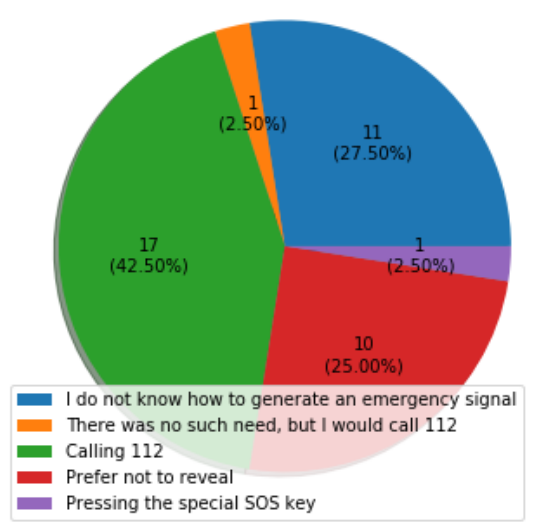

Figure 8. A summary regarding the use of a smartphone in an emergency situation.

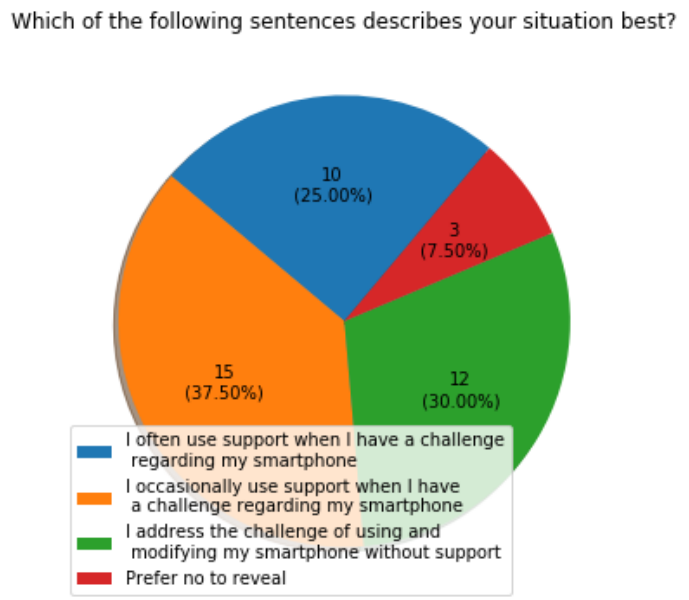

Figure 9. A summary of user's ability to solve problems independently.

Fig. 10 shows a summary of responses regarding the use of method for smartphone access control. Only three people use either finger biometrics or face recognition. Also the result for the "None of the above" answer seems surprising and perhaps this group of users does not protect their smartphones at all.

Fig. 11 shows a summary of the responses given regarding the method of user interaction with a smartphone. The vast majority use only the touch screen and only two people have declared that they use voice commands. This is quite surprising due to the fact that issuing voice commands significantly facilitates interaction with a smartphone. 
How do you unlock your smartphone?

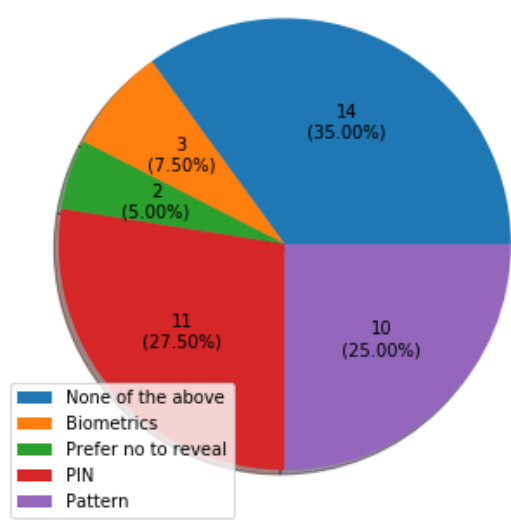

Figure 10. A summary of how the users lock their smartphones.
How do you interact with your smartphone?

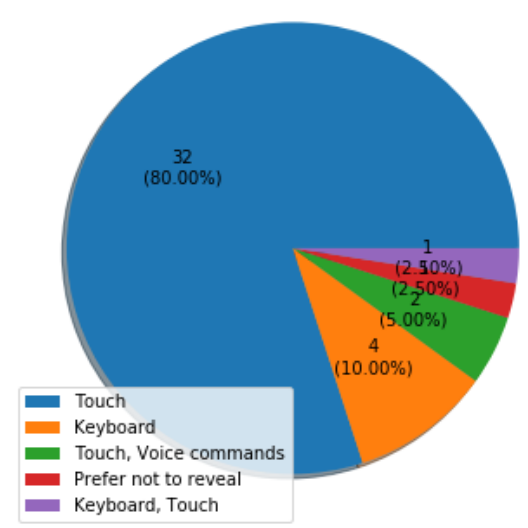

However, to the given open question about what special smartphone capabilities you use, the following responses were received:

- Simple mode in Huawei.

- Voice dictation.

- Bigger font, higher contrast.

- Bigger font (2 persons).

- None.

- Zoom.

In turn, to the question of what amenities you expect for a smartphone, two people gave the following answers:

- Simplicity.

- Voice interaction.

\section{Conclusions}

This article presents the results of a survey conducted on elderly people about the use of mobile devices. The received answers confirmed that with time seniors acquire more and more experience in the use of mobile devices. Greater experience leads to greater use of the smartphone to e.g. send short message or to use the camera. However, some smartphone functionalities (such as sending e-mails) are still not very popular among elderly people participating in the survey. 
Most of the respondents showed low knowledge of the important function of starting SOS signal, which is especially useful for elderly people. This result is an inspiration for the further research and development, in particular in the field of design and implementation of such alarm triggering mechanisms, which are characterized by high usability.

Alarming are also the answers to the question about the applied access control method on the mobile device. It is justified to build awareness among the elderly about the consequences that can be caused by the lack of an effective method of access control to the device. Notwithstanding the foregoing, an interesting direction of further work is the development of solutions which make the decision to switch into mode requiring the entering the unlock code by analysing user behaviour.

Obtained results of the conducted survey form the basis for conducting in-depth research projects in the field of mobile interfaces designed to meet the needs of elderly people.

\section{Acknowledgements}

We would like to express our deepest appreciation to all MMI Research Team members for supporting the research project devoted to interaction of elderly people with computer tools and systems. Moreover, we would like to thank Aleksander Kobylarek, PhD, from University of Wroclaw for valuable research tips concerning running electronic survey among elderly people.

\section{References}

1. Al-Razgan, M.S., Al-Khalifa, H.S., Al-Shahrani, M.D., and AlAjmi, H.H. (2012) TouchBased Mobile Phone Interface Guidelines and Design Recommendations for Elderly People: A Survey of the Literature. Lecture Notes in Computer Science, 7666, 568-574.

2. Arab, F., Malik, Y. and Abdulrazak, B. (2013). Evaluation of PhonAge: An Adapted Smartphone Interface for Elderly People. Lecture Notes in Computer Science, 8120, 547 554.

3. Badowska, S. (2016) Innowacyjność konsumentów seniorów w świetle badań własnych. Zarzadzanie $i$ Finanse Journal of Management and Finance, 14(1), 65-85.

4. Bhutta, Z.I., Sheikh, J.A., and Yousaf, A. (2018). Usage of Mobile Phones Amongst Elderly People in Pakistan. Advances in Intelligent Systems and Computing, 588, 621-630.

5. CBOS: Korzystanie z telefonów komórkowych, KOMUNIKAT z BADAŃ NR 99/2017. Available online https://www.cbos.pl/SPISKOM.POL/2017/K_099_17.PDF, 16.06.2019. 
6. Cearley, D., and Burke, B. Top 10 Strategic Technology Trends for 2019. Retrieved from https://www.gartner.com/smarterwithgartner/gartner-top-10-strategic-technology-trendsfor-2019, 15.06.2019.

7. de Oliveira C.D., de Mattos Fortes, R.P., and Barbosa, E.F. (2018) An Analysis of Crossword Learning: A Mobile Application for the Elderly. Lecture Notes in Computer Science, 10927, 501-515.

8. de Oliveira, D., Fioravanti, M.L., de Mattos Fortes, R.P., and Barbosa, E.F. (2018) Accessibility in mobile applications for elderly users: a systematic mapping. 48th Annual Frontiers in Education Conference, 1-9. doi 10.1109/FIE.2018.8659017.

9. García-Peñalvo, F.J., Conde, M.Á., and Matellán-Olivera, V. (2014). Mobile Apps for Older Users - The Development of a Mobile Apps Repository for Older People. Lecture Notes in Computer Science, 8524, 117-126.

10. García-Peñalvo, F.J., Conde, M.Á., and Matellán-Olivera, V. (2014) Mobile Apps for Older Users - The Development of a Mobile Apps Repository for Older People. Lecture Notes in Computer Science, 8524, 117-126.

11. Gordon, M., and Bigham, J. (2019). App Usage Predicts Cognitive Ability in Older Adults. CHI '19: Proceedings of CHI Conference on Human Factors in Computing Systems, 1-12. doi: $10.1145 / 3290605.3300398$.

12. Iqbal M.W., Ahmad N., and Shahzad, S.K. (2017) Usability evaluation of adaptive features in smartphones. Procedia Computer Science, 112, 2185-2194. doi 10.1016/ j.procs.2017.08.258.

13. Leme, R.R., Amaral, A.R., and Zaina, L.A.M. (2014). Interaction with mobile devices on social networks by elderly people: A survey in Brazil with Facebook. 2014 XL Latin American Computing Conference (CLEI), 1-7. doi: 10.1109/CLEI.2014.6965103.

14. Li, Q., and Luximon, Y. (2018) Understanding Older Adults' Post-adoption Usage Behavior and Perceptions of Mobile Technology. International Journal of Design, 12(3), 93-110.

Nasir, M.H.N.M.N., and Jomhari, H.H.N. (2008). The Use of Mobile Phones by Elderly: A Study in Malaysia Perspectives. Journal of Social Sciences, 4(5), 123-127. doi: 10.3844 jssp.2008.123.127.

15. Niemczyk, A. (2016) Seniorzy wobec nowych technologii. Studia Ekonomiczne. Uniwersytet Ekonomiczny w Katowicach. Ekonomia, 7(303), 102-113.

16. Nurgalieva, L., Jara Laconich, J.J., Baez, M., Casati, F., and Marchese, M. (2019). A Systematic Literature Review of Research-Derived Touchscreen Design Guidelines for Older Adults. IEEE Access, 7, 22035-22058. doi: 10.1109/ACCESS.2019.2898467.

17. Slavíček, T. (2014). Touch screen mobile user interface for seniors (Master's thesis). Prague: Czech Technical University in Prague, Faculty of Electrical Engineering.

18. Umańska, E. (2016) Smartfonowa edukacja seniorów. E-mentor, 5(67), 36-39. 
19. UN DESA: United Nations, Department of Economic and Social Affairs, Population Division (2015). World Population Ageing 2015 (ST/ESA/SER.A/390). Available online https://www.un.org/en/development/desa/population/publications/pdf/ageing/WPA2015_ Report.pdf, 15.06.2019.

20. Wong, C.Y, Khong, C.W., and Harold, Thwaites, H. (2010). Mobile User Interface for Seniors: An Impact of Ageing Population on Mobile Design. Design Principles \& Practice: An International Journal, 4(4), 231-249.

21. Zainal, A, Razak, F.H.A., and Ahmad, N.A. (2013) Older People and the Use of Mobile Phones: An Interview Study. 2013 International Conference on Advanced Computer Science Applications and Technologies, 390-395. doi: 10.1109/ACSAT.2013.83. 